\title{
Lycii cortex radicis extract inhibits glioma tumor growth in vitro and in vivo through downregulation of the Akt/ERK pathway
}

\author{
JI CHEON JEONG ${ }^{1}$, SAENG JAE KIM ${ }^{1}$, YONG KEUN KIM ${ }^{2}$, CHAE HWA KWON ${ }^{2}$ and KI HYUNG KIM ${ }^{3,4}$ \\ ${ }^{1}$ Department of Oriental Medicine, Dongguk University, Kyung Ju 780-714; Departments of ${ }^{2}$ Physiology, and \\ ${ }^{3}$ Obstetrics and Gynecology, College of Medicine, Pusan National University, Pusan 602-739; ${ }^{4}$ Biomedical Research \\ Institute and Pusan Cancer Center, Pusan National University Hospital, Pusan 602-739, Republic of Korea
}

Received October 29, 2011; Accepted December 22, 2011

DOI: $10.3892 /$ or.2012.1637

\begin{abstract}
Lycii cortex radicis (LCR) is a traditional Korean medicinal herb. The present study was undertaken to examine the effect of an LCR extract on glioma cell growth and to determine its molecular mechanism in U87MG human glioma cells. The LCR extract resulted in apoptotic cell death in a dose- and time-dependent manner. The LCR extract-induced cell death was associated with generation of reactive oxygen species (ROS). Western blot analysis showed that the LCR extract caused downregulation of Akt and ERK. The LCR-induced cell death was prevented by transfection with the constitutively active forms of Akt and MEK. Oral administration of LCR extracts in subcutaneous U87MG xenograft models reduced glioma tumor volume. Taken together, these findings suggest that the LCR extract results in human glioma cell death through mechanisms involving ROS generation, downregulation of Akt and ERK, and caspase activation in vitro and reduces glioma tumor growth in vivo. These data suggest that the LCR extract may serve as a potential therapeutic agent for malignant human glioblastomas.
\end{abstract}

\section{Introduction}

Glioblastoma is the most common and highly aggressive primary brain tumor and is characterized by marked angiogenesis and extensive tumor cell invasion into the normal brain parenchyma $(1,2)$. Glioblastoma is a rapidly growing, highly infiltrative tumor making complete surgical removal impossible. After diagnosis of glioblastoma multiforme, the median survival time of 9-12 months has remained unchanged despite aggressive treatment including surgical removal of the tumor, radiotherapy, and chemotherapy $(3,4)$. Since the loca-

Correspondence to: Dr Ki Hyung Kim, Department of Obstetrics and Gynecology, College of Medicine, Pusan National University, 1-10 Ami-Dong, Suh-Gu, Busan 602-739, Republic of Korea E-mail: ghkim@pusan.ac.kr

Key words: Lycii cortex radicis, apoptosis, reactive oxygen species, Akt/ERK, tumor growth, human glioma cells tion of tumors in the brain limits drug availability (5), the use of novel therapeutic approaches may be required.

Natural products derived from plants have recently received much attention as potential chemopreventive and chemotherapeutic agents. Among them great attention has been given to naturally occurring polyphenolic compounds such as flavonoids. These compounds may be potential candidates for cancer prevention and treatment in preclinical models and clinical trials (6-8). Considering that the use of synthetic agents in long-term chemopreventive strategies is associated with toxicity problems and leads to development of multidrug resistance, flavonoids may be a very promising group of compounds exerting the chemopreventive and chemotherapeutic effects.

Lycii cortex radicis (LCR) has been extensively used as a traditional Korean medicinal herb for centuries due to its biological activities such as cooling blood and bringing down fever (9). Previous studies have shown that the LCR extract improves insulin resistance and lipid metabolism in obesediabetic rats (10). Since it has been known that LCR contains a variety of physiologically active compounds such as apigenin, luteolin, kaempferol, quercetin, oleanolic acid, and urosolic acid $(11,12)$ which may have anticancer activities $(13-15)$, LCR may exert an inhibitory effect on tumor growth. However, little information is available regarding the effect of LCR on cancer cell growth.

The present study was undertaken to investigate whether the LCR extract affects cell growth and to characterize its molecular mechanism in U87MG human glioma cells. The results of the present study show that the LCR extract inhibits glioma tumor growth through apoptotic cell death mediated by down-regulation of the Akt/ERK pathway in vitro and in vivo.

\section{Materials and methods}

Reagents. N-acetylcysteine (NAC), Trolox, catalase, Hoechst 33258, 3-[4,5-dimethylthiazol-2-yl]-2,5-diphenyltetrazolium bromide (MTT), and propidium iodide were purchased from Sigma-Aldrich Chemical (St. Louis, MO, USA). Tween-20, U0126 and LY984002 were purchased from Calbiochem (San Diego, CA, USA). 2',7'-Dichlorofluorescein diacetate (DCFHDA) was obtained from Molecular Probes (Eugene, OR, USA). Antibodies were obtained from Cell Signaling Technology, 
Inc. (Beverly, MA, USA). All other chemicals were of the highest commercial grade available.

Preparation of the LCR extract. The LCR extract was prepared and authenticated by Dr Sun Dong Park (College of Oriental Medicine, Dongguk University, Kyung Ju, Korea). A voucher specimen (no. DGBS019) has been deposited in the Herbarium of Oriental Medicine, Dongguk University). The crushed LCR $(1,000 \mathrm{~g})$ was extracted 3 times each time with 3 volumes of methyl alcohol at $60^{\circ} \mathrm{C}$ for $24 \mathrm{~h}$. The extract was filtered and evaporated under a reduced pressure using a rotary evaporator to yield $72.97 \mathrm{~g}$ (yield $7.30 \%$ ).

Cell culture. U87MG cells were obtained from the American Type Culture Collection (Rockville, MD, USA) and maintained by serial passages in $75-\mathrm{cm}^{2}$ culture flasks (Costar, Cambridge, MA, USA). The cells were grown in Dulbecco's modified Eagle's medium (DMEM, Gibco-BRL, Invitrogen, Carsbad, CA, USA) containing $10 \%$ heat-inactivated fetal bovine serum (HyClone, Logan, UT, USA) at $37^{\circ} \mathrm{C}$ in humidified $95 \%$ air $/ 5 \%$ $\mathrm{CO}_{2}$ incubator. When the cultures reached confluence, subculture was prepared using a $0.02 \%$ EDTA- $0.05 \%$ trypsin solution. The cells were grown on tissue culture plates and used 1-2 days after plating when a confluent monolayer culture was achieved. Cells were treated with LCR extract in serum-free medium.

Measurement of cell viability and cell death. Cell viability was evaluated using an MTT assay (16). After washing the cells, the culture medium containing $0.5 \mathrm{mg} / \mathrm{ml}$ of MTT was added to each well. The cells were incubated for $2 \mathrm{~h}$ at $37^{\circ} \mathrm{C}$, the supernatant was removed and the formed formazan crystals in viable cells were solubilized with $0.11 \mathrm{ml}$ of dimethyl sulfoxide. A $0.1 \mathrm{ml}$ aliquot of each sample was then transfected to 96-well plates and the absorbance of each well was measured at $550 \mathrm{~nm}$ with an ELISA Reader (FLUOstar OPTIMA, BMG Labtech, Offenburg, Germany). Data were expressed as a percentage of control measured in the absence of LCR extract. Unless otherwise stated, the cells were exposed to $10 \mathrm{mg} / \mathrm{ml}$ LCR for $24 \mathrm{~h}$. Test reagents were added to the medium $30 \mathrm{~min}$ before exposure to the LCR extract.

Cell death was estimated by the trypan blue exclusion assay. The cells were harvested using $0.025 \%$ trypsin and incubated with $4 \%$ trypan blue solution. The number of viable and nonviable cells was counted using a hemocytometer under light microscopy. Cells failing to exclude the dye were considered non-viable.

Measurement of apoptosis. Cells were grown in 6-well plates and were treated as indicated. Then, attached and floating cells were pooled, pelleted by centrifugation, washed in PBS, and fixed with cold $70 \%$ ethanol containing $0.5 \%$ Tween- 20 at $4{ }^{\circ} \mathrm{C}$ overnight. Cells were washed and resuspended in $1.0 \mathrm{ml}$ of propidium iodide solution containing $100 \mu \mathrm{g}$ of RNase A/ml and $50 \mu \mathrm{g}$ propidium iodide $/ \mathrm{ml}$ and incubated for $30 \mathrm{~min}$ at $37^{\circ} \mathrm{C}$. Apoptotic cells were assayed using a FACSort BectonDickinson flow cytometer at $488 \mathrm{~nm}$ and data were analyzed with the CellQuest software. Cells with sub- $\mathrm{G}_{1}$ propidium iodide incorporation were considered as apoptotic. The percentage of apoptotic cells was calculated as the ratio of events on sub- $\mathrm{G}_{1}$ to events from the whole population.
Measurement of reactive oxygen species (ROS). The intracellular generation of ROS was measured using DCFH-DA. The nonfluorescent ester penetrates into the cells and is hydrolyzed to DCFH by the cellular esterases. The probe (DCFH) is rapidly oxidized to the highly fluorescent compound $2^{\prime} 7$ '-dichlorofluorescein (DCF) in the presence of cellular peroxidase and ROS, such as hydrogen peroxide or fatty acid peroxides. Cells cultured in 24-well plate were preincubated in the culture medium with $30 \mu \mathrm{M}$ DCFH-DA for $1 \mathrm{~h}$ at $37^{\circ} \mathrm{C}$. After the preincubation, the cells were exposed to $10 \mathrm{mg} / \mathrm{ml}$ LCR extract for various durations. Changes in DCF fluorescence was assayed using the FACSort Becton-Dickinson Flow Cytometer (Becton-Dickinson Bioscience, San Jose, CA, USA) and data were analyzed with the CellQuest software.

Western blot analysis. Cells were harvested at various times after treatment of the LCR extract and disrupted in lysis buffer (1\% Triton X-100, 1 mM EGTA, 1 mM EDTA, $10 \mathrm{mM}$ Tris-HCl, $\mathrm{pH}$ 7.4). Cell debris was removed by centrifugation at $10,000 \mathrm{xg}$ for $10 \mathrm{~min}$ at $4^{\circ} \mathrm{C}$. The resulting supernatants were resolved on a $12 \%$ SDS-PAGE under denatured reducing conditions and transferred to nitrocellulose membranes. The membranes were blocked with 5\% non-fat dried milk at room temperature for $30 \mathrm{~min}$ and incubated with primary antibodies. The membranes were washed and incubated with horseradish peroxidase-conjugated secondary antibody. The signal was visualized using enhanced chemiluminescence (Amersham, Buckinghamshire, UK).

In vivo tumor growth assay. U87MG cells $\left(2 \times 10^{6}\right)$ were injected subcutaneously into the right hind leg of 4-week male Balb/c nude mouse. After injection, animals were fed with 50 or $100 \mathrm{mg} / \mathrm{kg}$ LCR extract ( $\mathrm{n}=5)$ in $50 \mu \mathrm{l}$ saline or with $50 \mu \mathrm{l}$ saline (vehicle, $n=5$ ) by oral gavage daily. After 7 weeks, the tumors were excised and tumor volume was calculated using the equation: tumor volume $\left(\mathrm{mm}^{3}\right)=\left(\right.$ length $\mathrm{x}$ width $\left.{ }^{2}\right) \mathrm{x} \pi / 6$. Tumors were fixed in formalin, embedded in paraffin, and sectioned by standard methods for immunohistochemical analyses.

Immunohistochemistry. Paraffin-embedded tumor sections were deparaffinized and dehydrated through a series of graded alcohols. Sections were blocked with $8 \%$ BSA in PBS and incubated overnight at $4^{\circ} \mathrm{C}$ with rabbit anti-Ki-67 (1:500 dilution) antibody. Sections were washed and incubated with appropriate fluorescein (FITC) secondary antibodies at room temperature for $1 \mathrm{~h}$. After washing, counterstaining was carried out with Hoechst 33258 for 15 min. Sections were viewed under a fluorescence microscope (Leica, Wetzlar, Germany). The positive cells were counted and presented as the average of the four highest areas.

Terminal deoxynucleotidyl transferase-mediated dUTP nick end labeling (TUNEL) assay. The TUNEL assay was performed using an In Situ Cell Death Detection kit (Roche, Indianapolis, IN, USA) according to the manufacturer's instructions and pictures were captured on an inverted fluorescence microscope. Briefly, slides were deparaffinized and treated with permeabilization solution $(0.1 \%$ Triton X-100 + $0.1 \%$ sodium citrate) at $4^{\circ} \mathrm{C}$ for $2 \mathrm{~min}$ to enhance the staining. For detection of single- and double-stranded DNA breaks, 
$\mathbf{A}$
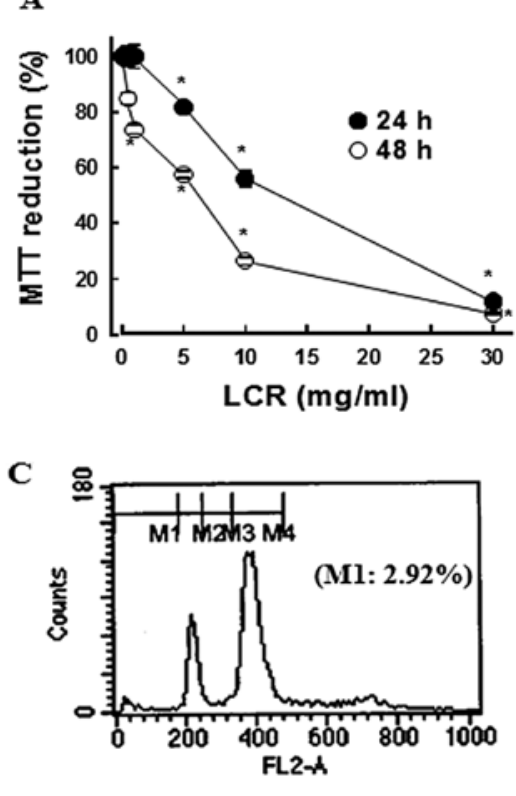

Control
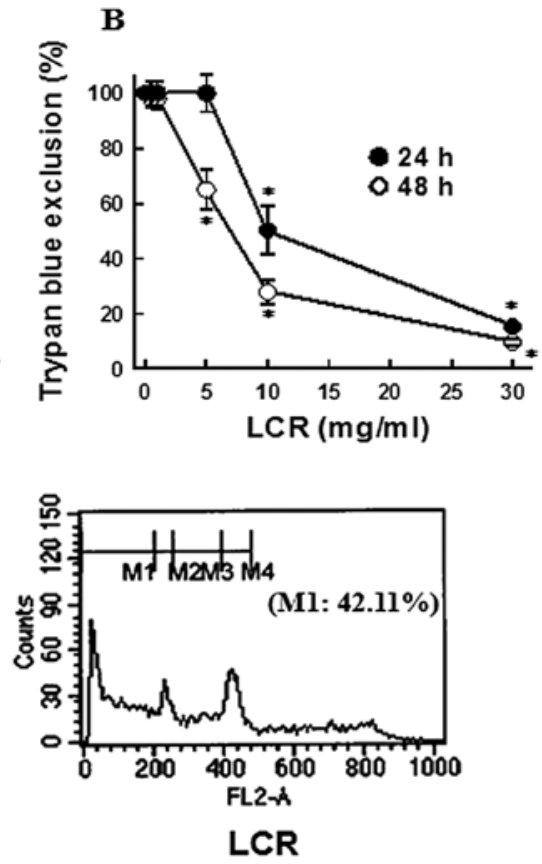

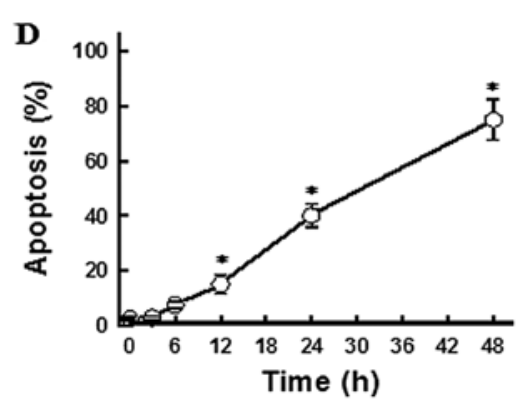

Figure 1. Effect of Lycii cortex radicis (LCR) extract on cell viability (A) and cell death (B). Cells were exposed to various concentrations of LCR extract for 24 and $48 \mathrm{~h}$. Cell viability and death were estimated by the MTT reduction assay and trypan blue exclusion. Data are the mean \pm SEM of four independent experiments performed in duplicate. ${ }^{*} \mathrm{P}<0.05$ compared with the control without the LCR extract. (C) Cells were exposed to $10 \mathrm{mg} / \mathrm{ml} \mathrm{LCR}$ extract for $24 \mathrm{~h}$. Apoptosis was estimated by flow cytometric analysis. Numbers indicate the percentage of cells with the sub-G $\mathrm{G}_{1}$ peak (M1 gated, apoptotic cells). (D) Quantitative results of LCR extract-induced apoptosis. Apoptosis was estimated by flow cytometric analysis. Data are the mean \pm SEM of four independent experiments performed in duplicate. ${ }^{*} \mathrm{P}<0.05$ compared with zero time.

slides were incubated for $1 \mathrm{~h}$ at $37^{\circ} \mathrm{C}$ with TUNEL reaction mixture (enzyme solution + labeling solution). Slides were stained with Hoechst 33258 for 15 min. TUNEL-positive cells were counted and expressed as the percentage of total cells.

Statistical analysis. The data are expressed as mean \pm SEM and the difference between the two groups was evaluated using the Student's t-test. Multiple group comparison was performed using one-way analysis of variance followed by the Tukey post-hoc test. A probability level of 0.05 was used to establish significance.

\section{Results}

Effect of LCR extract on cell viability and cell death. To determine the effect of the LCR extract on cell viability, cells were exposed to $1-30 \mathrm{mg} / \mathrm{ml}$ for 24 and $48 \mathrm{~h}$. The LCR extract caused loss of cell viability in a dose- and time-dependent manner as evidenced by a decrease in MTT reduction (Fig. 1A). After addition of $10 \mathrm{mg} / \mathrm{ml} \mathrm{LCR} \mathrm{extract} \mathrm{for} 24$ and $48 \mathrm{~h}$, the cell viability decreased up to $\sim 55$ and $25 \%$ of control, respectively. To ascertain whether reduction in cell viability was attributed to cell death, a trypan blue exclusion assay was performed. As shown in Fig. 1B, the LCR extract induced cell death in a dose- and time-dependent manner, similarly to those estimated by the MTT assay, suggesting that the reduction in cell viability by the LCR extract was mainly due to induction of cell death.

To determine whether the LCR extract-induced cell death was attributed to apoptosis, cells were exposed to $10 \mathrm{mg} /$ $\mathrm{ml} \mathrm{LCR}$ extract for $24 \mathrm{~h}$, and flow cytometric analysis was performed for cells exposed to LCR extract. The sub- $\mathrm{G}_{1}$ peak (M1 gate) that represents a population of cells with reduced DNA staining, probably due to DNA fragmentation, increased from $2.92 \%$ in the control to $41.11 \%$ in the LCR extract-treated cells (Fig. 1C). The LCR extract induced glioma cell apoptosis in a time-dependent manner (Fig. 1D). These data suggest that the LCR extract-induced cell death was largely attributed to induction of apoptosis.

Role of ROS in LCR extract-induced cell death. To determine whether the LCR extract induces ROS generation in human 
$\mathbf{A}$
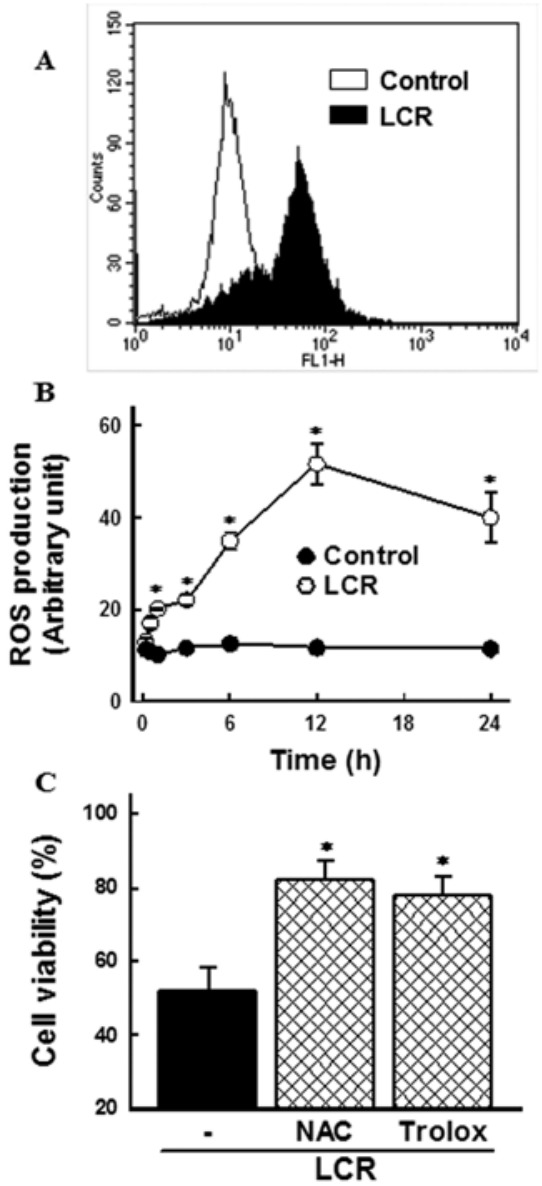

Figure 2. Role of reactive oxygen species (ROS) generation in Lycii cortex radicis (LCR) extract-induced cell death. Cells were exposed to $10 \mathrm{mg} / \mathrm{ml}$ LCR extract for $12 \mathrm{~h} \mathrm{(A)} \mathrm{and} \mathrm{for} \mathrm{various} \mathrm{times} \mathrm{(B)} \mathrm{and} \mathrm{the} \mathrm{DCF} \mathrm{fluorescence}$ intensity was measured by a flow cytometer. Data in (B) are mean \pm SEM of four independent experiments performed in duplicate. ${ }^{*} \mathrm{P}<0.05$ compared with the control. (C) Cells were exposed to $10 \mathrm{mg} / \mathrm{ml}$ of the LCR extract for $24 \mathrm{~h}$ in the presence or absence of $2 \mathrm{mM} \mathrm{N}$-acetylcysteine (NAC) and $0.5 \mathrm{mM}$ Trolox. Cell viability was estimated by the MTT reduction assay. Data are the mean \pm SEM of four independent experiments performed in duplicate. ${ }^{*} \mathrm{P}<0.05$ compared with the LCR extract alone.

glioma cells, cells were exposed to the LCR extract and changes in DCF fluorescence were measured by flow cytometry. ROS generation increased in cells exposed to $10 \mathrm{mg} / \mathrm{ml} \mathrm{LCR}$ extract for $12 \mathrm{~h}$ as assessed by increased DCFH-DA oxidation (Fig. 2A). To ascertain if ROS generation by the LCR extract is dependent on exposure time, cells were exposed to $10 \mathrm{mg} / \mathrm{ml}$ LCR extract for various times. As shown in Fig. 2B, the LCR extract increased ROS generation in a time-dependent fashion up to $12 \mathrm{~h}$. To evaluate whether ROS generation is involved in the LCR extract-induced cell death, the effect of antioxidants NAC and Trolox on the cell viability was examined. The LCR extract-induced loss of cell viability was prevented by these antioxidants (Fig. 2C), indicating that the LCR extract-induced cell death is associated with ROS generation in human glioma cells.

Effect of LCR extract on activation of cell survival kinases. Akt and ERK play a pivotal role in cell proliferation, differentiation, and survival (17-19). If these kinases are downregulated by the LCR extract, cell death could be induced. To assess this possibility, activity of these kinases was evaluated by detecting their phosphorylation forms. Cells were exposed to $10 \mathrm{mg} / \mathrm{ml}$ LCR extract for various times and changes in the activation of Akt and ERK were estimated by western blot analysis using antibodies specific to the respective phosphorylated form. The LCR extract caused a decrease in the activation of these kinases after $1 \mathrm{~h}$ of treatment (Fig. 3A and B).

To determine whether downregulation of Akt and ERK is responsible for the LCR extract-induced cell death, we examined the effect of the LCR extract on cell viability in cells transfected with constitutively active forms of Akt (caAkt) and MEK (caMEK), the upstream kinase of ERK. The efficiency of transfection was confirmed by western blot analysis. In cells transfected with caAkt and caMEK, phosphorylation of Akt and ERK was significantly increased as compared with cells transfected with empty vector (Fig. 3C). Transfection of caAkt and caMEK effectively prevented the LCR extract-induced cell death (Fig. 3D), suggesting that downregulation of Akt and ERK plays a critical role in the LCR extract-induced cell death.

To ascertain if the downregulation of Akt and ERK by the LCR extract is associated with ROS generation, the effect of antioxidants on the downregulation of these kinases was examined. As shown in Fig. 3E, the LCR extract-induced inhibition of Akt and ERK phosphorylation was blocked by NAC and catalase. These results suggest that ROS generation acts upstream for downregulation of Akt and ERK in cells exposed to the LCR extract.

Effect of the LCR extract on glioma tumor growth in vivo. To determine the antineoplastic effect of the LCR extract in vivo, U87MG cells were injected subcutaneously into Balb/c nude mouse. After injection, the LCR extract (50 or $100 \mathrm{mg} / \mathrm{kg}$ ) or vehicle (saline) were administered by oral gavage daily. All vehicle mice developed subcutaneous tumors with volume of $688 \mathrm{~mm}^{3}$ after 7 weeks. LCR extract administration caused reduction of tumor volume in a dose-dependent fashion (Fig. 4A). There were no differences in body weight between the two groups (data not shown).

To assess whether the LCR extract inhibits tumor proliferation in vivo, Ki-67 expression was evaluated. Treatment of LCR extract decreased the proliferative rate of tumor cells in a dose-dependent manner (Fig. 4B), supporting the results obtained in vitro. We also obtained evidence that the LCR extract significantly increased apoptosis (Fig. 4C).

To determine whether ERK and Akt are downregulated by the LCR extract in vivo, phosphorylation of ERK and Akt was examined in tumor tissues of animals treated with $50 \mathrm{mg} / \mathrm{kg}$ LCR extract. Similarly to in vitro data, treatment of the LCR extract inhibited activation of ERK and Akt (Fig. 4D).

\section{Discussion}

Inhibition of cancer cell growth through induction of differentiation and apoptosis may be an attractive approach to human cancer therapy. It has been reported that natural products derived from plants exert anticancer effects via induction of apoptosis, although the molecular mechanisms by which they induce apoptosis have not been yet clarified $(20,21)$. Recently, 
$\mathbf{A}$

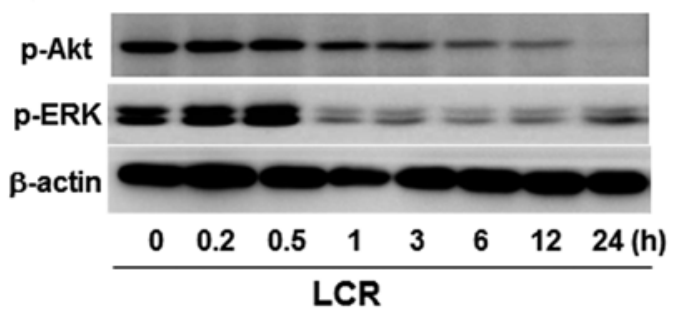

B

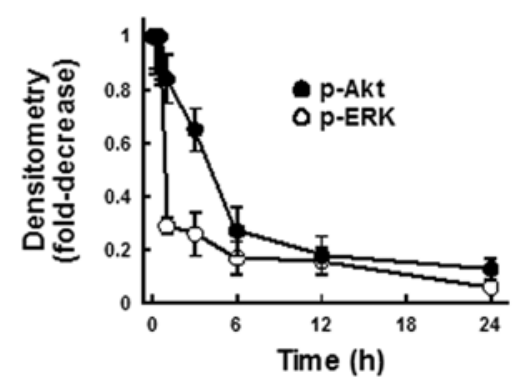

C

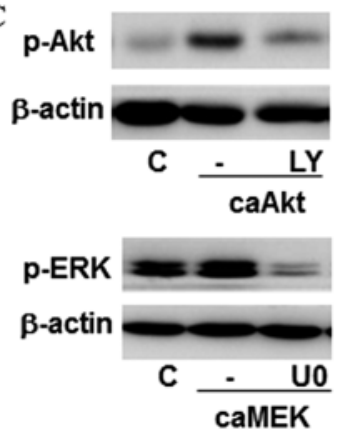

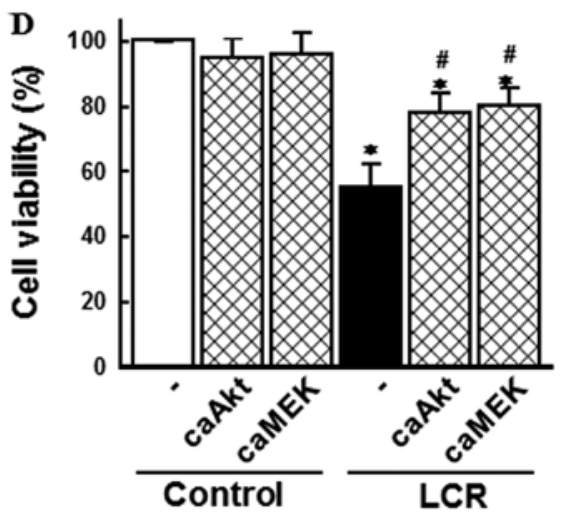

E

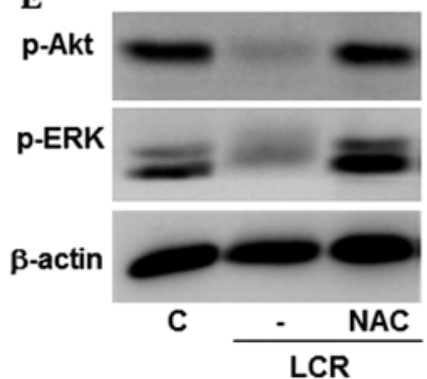

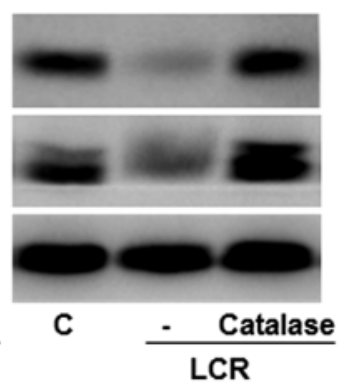

Figure 3. Effects of Lycii cortex radicis (LCR) extract on the activation of Akt and ERK. Representative (A) and quantitative (B) results of three independent experiments. Cells were exposed to $10 \mathrm{mg} / \mathrm{ml}$ LCR extract for various times. Activation of ERK and Akt was estimated by western blot analysis. $\beta$-actin was used as a loading control. Data are the mean \pm SEM of three independent experiments. (C) Cells were transfected with empty vector (EV), constitutively active forms of MEK (caMEK), and Akt (caAkt) in the presence or absence of U0126 (U0) and LY984002, respectively. The efficiency of transfection was estimated by western blot analysis. (D) Cells were transfected as described above and exposed to $10 \mathrm{mg} / \mathrm{ml} \mathrm{LCR}$ extract for $24 \mathrm{~h}$. Cell viability was estimated by the MTT assay. Data are the mean \pm SEM of four independent experiments performed in duplicate. ${ }^{*} \mathrm{P}<0.05$ compared with the empty vector $(\mathrm{EV})$ of the control; ${ }^{*} \mathrm{P}<0.05$ compared with EV exposed to the LCR extract. (E) Cells were exposed to $10 \mathrm{mg} / \mathrm{ml} \mathrm{LCR} \mathrm{extract} \mathrm{for} 24 \mathrm{~h}$ in the presence or absence of $2 \mathrm{mM} \mathrm{N}$-acetylcysteine (NAC) and 500 units/ml catalase. Activation of ERK and Akt was estimated by western blot analysis.

we observed that mulberry fruit (Moris fructus) extract, a traditional Korean medicinal herb, induces human glioma cell death through the ROS-dependent mitochondrial pathway and inhibits glioma tumor growth (22). In the present study, we examined the effect of the LCR extract on glioma cell growth. The LCR extract has been extensively used as a traditional Korean medicinal herb for centuries (9). Although the LCR extract has been shown to improve insulin resistance and lipid metabolism in obese-diabetic rats (10), the effect of LCR on glioma cell growth has not been explored.

The present study demonstrated that the LCR extract caused loss of cell viability in a dose-and time-dependent manner and its effect was attributed to apoptotic cell death (Fig. 1).

Flavonoids, the major component of natural products derived from plants, behave as an antioxidant (20) or a pro- oxidant generating ROS (23-25). We previously observed that flavonoids such as silibinin and kaempferol induce cell death through ROS generation $(14,15)$. Similarly, the LCR extract in the present study increased ROS generation and the LCR extract-induced cell death was prevented by antioxidants (Fig. 2), indicating that ROS production plays an important role in the LCR extract-induced glioma cell death.

The Akt signaling pathway mediates glioma cell survival and growth (26). The aberrant activation of Akt signaling has been identified as crucial to the malignant features of glioblastoma multiforme such as rapid tumor growth, invasiveness, resistance to cytotoxic treatments, and massive neovascularization (27-29). Therefore, regulation of the Akt signaling pathway may be a promising target for the clinical management of patients with glioma. Indeed, Akt was highly activated in U87MG human glioma cells and the Akt activa- 
A
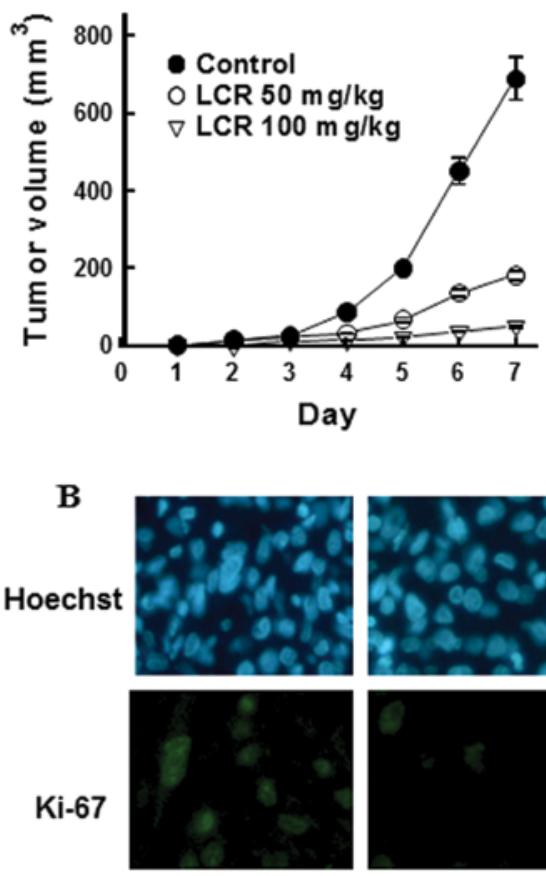

Vehicle
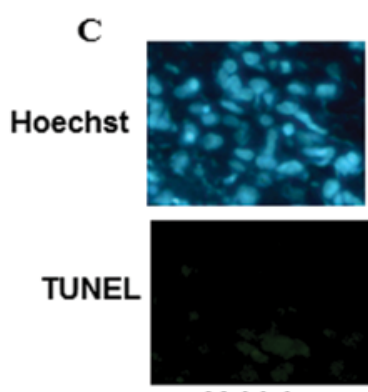

Vehicle
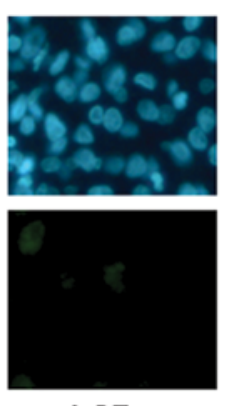

LCR

(50 $\mathrm{mg} / \mathrm{kg})$
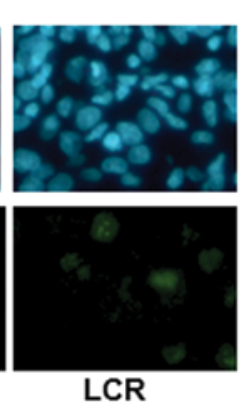

$(50 \mathrm{mg} / \mathrm{kg})$
D
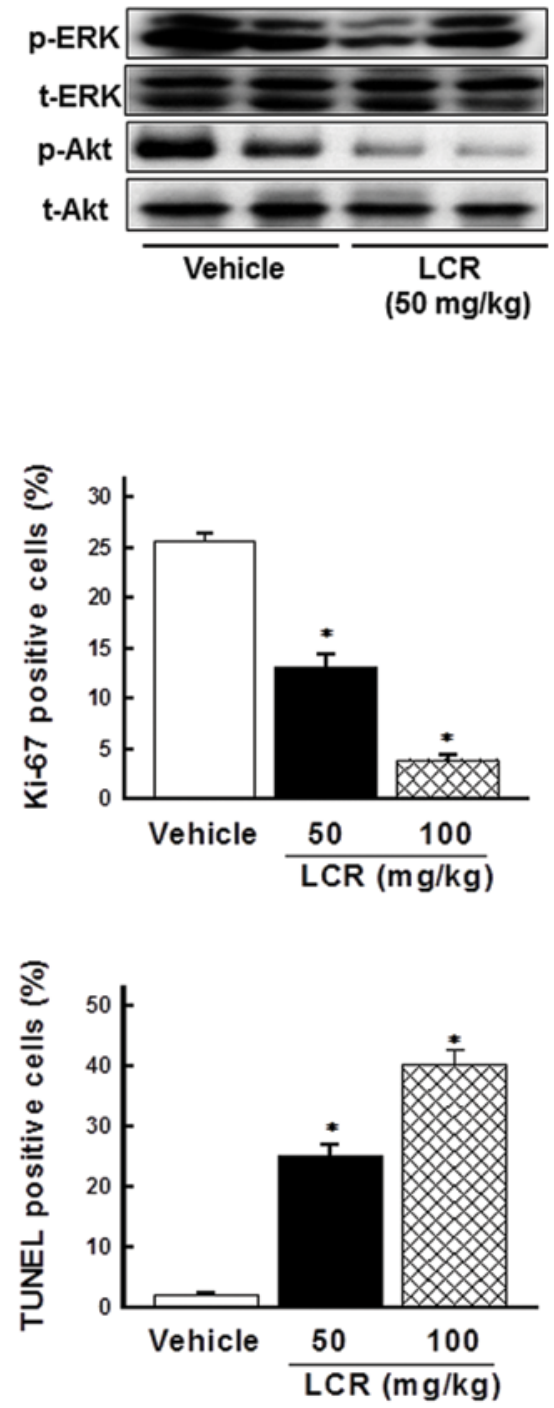

Figure 4. Effect of Lycii cortex radicis (LCR) extracts on tumor growth in the subcutaneous U87MG xenograft mouse model. U87MG cells $\left(2 \mathrm{x} 10^{6}\right)$ were injected subcutaneously into the right hind leg of 4 -week male nude mice. After injection, LCR extracts $(50 \mathrm{or} 100 \mathrm{mg} / \mathrm{kg}) \mathrm{or}$ vehicle (DMSO, $0.1 \%$ final concentration) were administered by oral gavage daily. (A) After 7 weeks, the tumors were excised and tumor volume was calculated using the equation: tumor volume $\left(\mathrm{mm}^{3}\right)=\left(\right.$ length $\mathrm{x}$ width $\left.{ }^{2}\right) \mathrm{x} \pi / 6$. Reduction in tumor volume by the LCR extract was associated with (B) inhibition of cell proliferation and (C) induction of apoptosis. Bar graphs represent the mean \pm SEM of five animals in each group. (D) Western blot analysis of the inhibition of ERK and Akt activation by the LCR extract.

tion was inhibited by the LCR extract (Fig. 3A) and the LCR extract-induced cell death was also prevented by transfection with caAkt (Fig. 3D). These data imply that downregulation of Akt plays an important role in the LCR extract-induced glioma cell death.

ERK is activated by a variety of extracellular signals including mitogens contributes to the proliferative responses in cells, and is considered to be an essential common element of mitogenic signaling (17,30). Its constitutive expression causes cell transformation and plays a putative role in the carcinogenesis process and drug resistance (31-33). However, the effect of flavonoids on ERK activation is controversial. Activation of ERK is inhibited by flavonoids in vascular smooth muscle cells (34), human epidermal carcinoma cells (35), and neuronal cells (36), whereas it is increased following flavonoid treatment in lung cancer cells (37). Previously, we observed that ERK is activated by silibinin (15) and inhibited by kaempferol (14) in human glioma cells. These studies suggest that the effect of flavonoids on ERK activation may be dependent on cell types and flavonoid structures. These data may support reports that flavonoid-induced inhibition of phosphatidylinositol 3-kinase and protein kinase $\mathrm{C}$ is dependent on flavonoid structures (38). In the present study, the LCR extract caused an inhibition of ERK phosphorylation (Fig. 3A) and the LCR extract-induced cell death was prevented by transfection of caMEK (Fig. 3D). The data imply that downregulation of the ERK signaling pathway plays an important role in the LCR extract-induced glioma cell death.

ROS induce the activation of multiple signaling pathways including Akt and ERK, leading to cell survival or cell death (39). On the other hand, the ability of ROS to trigger downregulation of the ERK and Akt pathway has also been reported 
$(40,41)$. In the present study, inhibition of Akt and ERK by LCR extract was blocked by the antioxidants NAC and catalase (Fig. 3E). These data suggest that ROS generation acts upstream of downregulation of ERK and Akt in cells exposed to the LCR extract.

To evaluate the antineoplastic effect of the LCR extract in vivo, tumor growth after subcutaneous implantation of U87MG cells was examined in nude mice. Oral LCR extract treatment markedly reduced tumor volume (Fig. 4A). Reduction in tumor volume by the LCR extract was associated with inhibition of cell proliferation (Fig. 4B) and induction of apoptosis (Fig. 4C). Inhibition of ERK and Akt activation by the LCR extract was confirmed in in vivo experiments (Fig. 4D).

In conclusion, the present study demonstrated that the LCR extract induced human glioma cell death through ROS-dependent downregulation of the Akt/ERK pathway. Oral LCR extract administration resulted in consistent regression of subcutaneous glioma tumors through inhibition of proliferation and induction of apoptosis in nude mice. These results suggest that the LCR extract may be a potential candidate for glioblastoma treatment.

\section{Acknowledgements}

This study was supported by a grant from the National R\&D Program for Cancer Control, Ministry for Health, Welfare and Family affairs, Republic of Korea (0920050).

\section{References}

1. Ohgaki H and Kleihues P: Population-based studies on incidence, survival rates, and genetic alterations in astrocytic and oligodendroglial gliomas. J Neuropathol Exp Neurol 64: 479-489, 2005.

2. Surawicz TS, Davis F, Freels S, Laws ER Jr and Menck HR: Brain tumor survival: results from the National Cancer Data Base. J Neurooncol 40: 151-160, 1998.

3. DeAngelis LM: Brain tumors. N Engl J Med 344: 114-123, 2001.

4. Sanai N, Alvarez-Buylla A and Berger MS: Neural stem cells and the origin of gliomas. N Engl J Med 353: 811-822, 2005.

5. Muldoon LL, Soussain C, Jahnke K, Johanson C, Siegal T, Smith QR, Hall WA, Hynynen K, Senter PD, Peereboom DM and Neuwelt EA: Chemotherapy delivery issues in central nervous system malignancy: a reality check. J Clin Oncol 25: 2295-2305, 2007.

6. Feng R, Lu Y, Bowman LL, Qian Y, Castranova V and Ding M: Inhibition of activator protein-1, NF-kappaB, and MAPKs and induction of phase 2 detoxifying enzyme activity by chlorogenic acid. J Biol Chem 280: 27888-27895, 2005.

7. Feng R, Ni HM, Wang SY, Tourkova IL, Shurin MR, Harada H and Yin XM: Cyanidin-3-rutinoside, a natural polyphenol antioxidant, selectively kills leukemic cells by induction of oxidative stress. J Biol Chem 282: 13468-13476, 2007.

8. Surh YJ: Cancer chemoprevention with dietary phytochemicals. Nat Rev Cancer 3: 768-780, 2003.

9. Lee SI: Herbs. Medical Herb Co., Seoul 133-134, 1983

10. Ye Z, Huang Q, Ni HX and Wang D: Cortex Lycii Radicis extracts improve insulin resistance and lipid metabolism in obese-diabetic rats. Phytother Res 22: 1665-1670, 2008.

11. Potterat O: Goji (Lycium barbarum and L. chinense): phytochemistry, pharmacology and safety in the perspective of traditional uses and recent popularity. Planta Med 76: 7-19, 2010.

12. Li G, Zhang XA, Zhang JF, Chan CY, Yew DT, He ML, Lin MC Leung PC and Kung HF: Ethanol extract of Fructus Ligustri Lucidi promotes osteogenesis of mesenchymal stem cells. Phytother Res 24: 571-576, 2010.

13. Kim KH, Seo HS, Choi HS, Choi I, Shin YC and Ko SG: Induction of apoptotic cell death by ursolic acid through mitochondrial death pathway and extrinsic death receptor pathway in MDA-MB-231 cells. Arch Pharm Res 34: 1363-1372, 2011.
14. Jeong JC, Kim MS, Kim TH and Kim YK: Kaempferol induces cell death through ERK and Akt-dependent down-regulation of XIAP and survivin in human glioma cells. Neurochem Res 34: 991-1001, 2009.

15. Kim KW, Choi CH, Kim TH, Kwon CH, Woo JS and Kim YK: Silibinin inhibits glioma cell proliferation via $\mathrm{Ca}_{2}{ }^{+} / \mathrm{ROS} / \mathrm{MAPK}-$ dependent mechanism in vitro and glioma tumor growth in vivo. Neurochem Res 34: 1479-1490, 2009.

16. Denizot F and Lang R: Rapid colorimetric assay for cell growth and survival. Modifications to the tetrazolium dye procedure giving improved sensitivity and reliability. J Immunol Methods 89: 271-277, 1986.

17. Xia Z, Dickens M, Raingeaud J, Davis RJ and Greenberg ME: Opposing effects of ERK and JNK-p38 MAP kinases on apoptosis. Science 270: 1326-1331, 1995.

18. Cobb MH: MAP kinase pathways. Prog Biophys Mol Biol 71: 479-500, 1999.

19. Coffer PJ, Jin J and Woodgett JR: Protein kinase B (c-Akt): a multifunctional mediator of phosphatidylinositol 3-kinase activation. Biochem J 335: 1-13, 1998.

20. Ren W, Qiao Z, Wang H, Zhu L and Zhang L: Flavonoids: promising anticancer agents. Med Res Rev 23: 519-534, 2003.

21. Ramos S: Effects of dietary flavonoids on apoptotic pathways related to cancer chemoprevention. J Nutr Biochem 18: 427-442, 2007.

22. Jeong JC, Jang SW, Kim TH, Kwon CH and Kim YK: Mulberry fruit (Moris fructus) extracts induce human glioma cell death in vitro through ROS-dependent mitochondrial pathway and inhibits glioma tumor growth in vivo. Nutr Cancer 62: 402-412, 2010.

23. Miura YH, Tomita I, Watanabe T, Hirayama T and Fukui S: Active oxygens generation by flavonoids. Biol Pharm Bull 21: 93-96, 1998.

24. Wang IK, Lin-Shiau SY and Lin JK: Induction of apoptosis by apigenin and related flavonoids through cytochrome c release and activation of caspase-9 and caspase-3 in leukaemia HL-60 cells. Eur J Cancer 35: 1517-1525, 1999.

25. Shen SC, Ko CH, Tseng SW, Tsai SH and Chen YC: Structurally related antitumor effects of flavanones in vitro and in vivo: involvement of caspase 3 activation, p21 gene expression, and reactive oxygen species production. Toxicol Appl Pharmacol 197: 84-95, 2004.

26. Wong ML, Kaye AH and Hovens CM: Targeting malignant glioma survival signalling to improve clinical outcomes. J Clin Neurosci 14: 301-308, 2007.

27. Chekenya M, Krakstad C, Svendsen A, Netland IA, Staalesen V, Tysnes BB, Selheim F, Wang J, Sakariassen PO, Sandal T, et al: The progenitor cell marker NG2/MPG promotes chemoresistance by activation of integrin-dependent PI3K/Akt signaling. Oncogene 27: 5182-5194, 2008.

28. Knobbe CB, Merlo A and Reifenberger G: Pten signaling in gliomas. Neuro Oncol 4: 196-211, 2002.

29. Opel D, Westhoff MA, Bender A, Braun V, Debatin KM and Fulda S: Phosphatidylinositol 3-kinase inhibition broadly sensitizes glioblastoma cells to death receptor- and drug-induced apoptosis. Cancer Res 68: 6271-6280, 2008.

30. Pearson G, Robinson F, Beers Gibson T, Xu BE, Karandikar M, Berman K and Cobb MH: Mitogen-activated protein (MAP) kinase pathways: regulation and physiological functions. Endocr Rev 22: 153-183, 2001.

31. Groom LA, Sneddon AA, Alessi DR, Dowd S and Keyse SM: Differential regulation of the MAP, SAP and RK/p38 kinases by Pyst1, a novel cytosolic dual-specificity phosphatase. EMBO J 15: 3621-3632, 1996.

32. Kortenjann M, Thomae O and Shaw PE: Inhibition of v-raf-dependent c-fos expression and transformation by a kinasedefective mutant of the mitogen-activated protein kinase Erk2. Mol Cell Biol 14: 4815-4824, 1994.

33. Brunet A, Pages G and Pouyssegur J: Constitutively active mutants of MAP kinase kinase (MEK1) induce growth factorrelaxation and oncogenicity when expressed in fibroblasts. Oncogene 9: 3379-3387, 1994.

34. Moon SK, Cho GO, Jung SY, Gal SW, Kwon TK, Lee YC, Madamanchi NR and Kim CH: Quercetin exerts multiple inhibitory effects on vascular smooth muscle cells: role of ERK1/2, cell-cycle regulation, and matrix metalloproteinase-9. Biochem Biophys Res Commun 301: 1069-1078, 2003. 
35. Singh RP, Tyagi AK, Zhao J and Agarwal R: Silymarin inhibits growth and causes regression of established skin tumors in SENCAR mice via modulation of mitogen-activated protein kinases and induction of apoptosis. Carcinogenesis 23: 499-510, 2002.

36. Spencer JP, Rice-Evans C and Williams RJ: Modulation of prosurvival Akt/protein kinase B and ERK1/2 signaling cascades by quercetin and its in vivo metabolites underlie their action on neuronal viability. J Biol Chem 278: 34783-34793, 2003.

37. Nguyen TT, Tran E, Nguyen TH, Do PT, Huynh TH and Huynh $\mathrm{H}$ : The role of activated MEK-ERK pathway in quercetininduced growth inhibition and apoptosis in A549 lung cancer cells. Carcinogenesis 25: 647-659, 2004.

38. Agullo G, Gamet-Payrastre L, Manenti S, Viala C, Remesy C, Chap $\mathrm{H}$ and Payrastre B: Relationship between flavonoid structure and inhibition of phosphatidylinositol 3-kinase: a comparison with tyrosine kinase and protein kinase $\mathrm{C}$ inhibition. Biochem Pharmacol 53: 1649-1657, 1997.
39. Martindale JL and Holbrook NJ: Cellular response to oxidative stress: signaling for suicide and survival. J Cell Physiol 192: 1-15, 2002.

40. Yang HY, Kim J, Chung GH, Lee JC and Jang YS: Cross-linking of MHC class II molecules interferes with phorbol 12,13-dibutyrate-induced differentiation of resting $\mathrm{B}$ cells by inhibiting Rac-associated ROS-dependent ERK/p38 MAP kinase pathways leading to NF-kappaB activation. Mol Immunol 44: 1577-1586, 2007.

41. Su YT, Chang HL, Shyue SK and Hsu SL: Emodin induces apoptosis in human lung adenocarcinoma cells through a reactive oxygen species-dependent mitochondrial signaling pathway. Biochem Pharmacol 70: 229-241, 2005. 